\title{
EFEITO DA ORIENTAÇÃO PARA O MERCADO SOBRE A LUCRATIVIDADE DA EMPRESA
}

RESUMO

Acadêmicos e profissionais de marketing vêm observando, há mais de três décadas, que o desempenho empresarial é afetado pela orientação para o mercado, mas até hoje não há uma medida válida da orientação para o mercado nem análise sistemática de seu efeito sobre o desempenho das empresas. Os autores relatam o desenvolvimento de uma medida válida de orientação para o mercado e analisam seu efeito sobre a lucratividade de uma empresa. Usando uma amostra de 140 unidades de negócio composta de empresas de commodities e de não commodities, eles identificam o substancial efeito positivo da orientação para o mercado sobre a lucratividade dos dois tipos de empresa.

\section{John C. Narver \\ University of Washington \\ Stanley F. Slater \\ Colorado State University}

\begin{abstract}
Marketing academicians and practitioners have been observing for more than three decades that business performance is affected by market orientation, yet to date there has been no valid measure of a market orientation and hence no systematic analysis of its effect on a business's performance. The authors report the development of a valid measure of market orientation and analyze its effect on a business's profitability. Using a sample of 140 business units consisting of commodity products businesses and noncommodity businesses, they find a substantial positive effect of a market orientation on the profitability of both types of businesses.
\end{abstract}

PALAVRAS-CHAVE Orientação para o mercado, desempenho empresarial, medição, marketing, lucratividade.

KEYWORDS Market orientation, business performance, measure, marketing, profitability. 
Uma empresa que intensifique sua orientação para o mercado terá melhor desempenho no mercado. Essa máxima vem sendo constantemente proferida por acadêmicos e profissionais de marketing há mais de 30 anos (veja, por exemplo, Kotler e Andreasen, 1987; Levitt, 1960; Webster, 1988). A julgar pela atenção que recebe de profissionais e acadêmicos em discursos, livros e artigos científicos, a orientação para o mercado representa a própria alma da administração de marketing e da estratégia modernas. Mas até hoje ninguém desenvolveu uma medida válida da orientação para o mercado ou avaliou sua influência sobre o desempenho empresarial. Assim, profissionais que procurem implementar uma orientação para o mercado carecem de orientação específica sobre o que seria, exatamente, uma orientação para o mercado e qual poderia ser seu real efeito sobre o desempenho empresarial.

Relatamos neste artigo um estudo exploratório em que desenvolvemos uma medida válida da orientação para o mercado e analisamos seus efeitos sobre a lucratividade das empresas. Primeiramente, discutimos a relação entre vantagem competitiva sustentável e orientação para o mercado, e por que uma orientação para o mercado é a cultura empresarial mais eficaz e eficiente na criação de valor superior para o cliente. Em seguida, lançamos os componentes hipotéticos de uma orientação para o mercado e descrevemos os testes usados para determinar a validade da medida de orientação para o mercado enquanto construto. Depois discutimos a relação esperada entre orientação para o mercado e lucratividade empresarial, e as relações esperadas entre oito variáveis de controle e a lucratividade empresarial. Especificamos um modelo de efeitos independentes e examinamos as relações observadas entre lucratividade empresarial e orientação para o mercado e as oito variáveis independentes, comparando, em cada caso, as relações observadas com as hipotéticas. Após resumir as conclusões, discutimos as limitações do estudo e as implicações para pesquisas futuras.

\section{ORIENTAÇÃO PARA 0 MERCADO E DESEMPENHO: MODELO CONCEITUAL}

Para atingir um desempenho de mercado consistentemente superior ao normal, uma organização deve criar uma vantagem competitiva sustentável (VCS) (Aaker, 1989, p. 91; Porter, 1985, p. xv). Ou seja, precisa criar um valor superior sustentável para seus clientes. A idéia da VCS é o de que, para adquirir o produto $\mathrm{X}$, o comprador deve ter a percepção de que o valor da oferta para si, ou seja, a solução proposta para suas necessidade, supera o valor esperado de qualquer solução alternativa Para saber mais sobre as origens analíticas do VCS, veja, por exemplo, Alderson, 1957; Chamberlin, 1933.

Para o comprador, o valor da oferta de um vendedor é a diferença entre os benefícios esperados de tal oferta e aquilo que o comprador considera o custo total de aquisição e uso (Zeithaml, 1988). Um vendedor, qualquer que seja, goza de diversas oportunidades alternativas de criação de valor adicional para o comprador por meio do aumento dos benefícios a ele concedidos e/ou da redução dos custos totais de aquisição e uso (por exemplo, Forbis e Metha, 1981).

O desejo de criar superioridade no valor e obter uma VCS para o cliente leva as empresas a criar e manter uma cultura capaz de produzir os comportamentos desejados. O mercado é a cultura organizacional (isto é, cultura e clima, Deshpande e Webster, 1989) de maior eficácia e eficiência na criação dos comportamentos necessários para criar superioridade no valor para os compradores e, assim, um desempenho continuadamente superior para a empresa (Assker, 1988; Jaworski e Kohli, 1993; Kotler, 1984; Kotler e Andreasen, 1987; Peters e Austin, 1985; Peters e Waterman, 1982; Shapiro, 1988; Webster, 1988).

Um vendedor orientado para o mercado sabe que há muitas fontes potenciais de VCS com a criação de benefícios adicionais para seus clientes e de numerosas formas de redução dos custos totais de aquisição e uso (Aaker, 1988; Hall, 1980; Porter, 1985). Assim, uma empresa orientada para o mercado examina constantemente essas fontes alternativas de VCS para ver como pode ser mais eficaz na criação de uma superioridade sustentável em valor para seus clientes atuais e potenciais. Para maximizar seu desempenho a longo prazo, a empresa sabe que precisa construir e manter uma relação duradoura e mutuamente benéfica com seus compradores. Assim, um vendedor orientado para o mercado decide a melhor maneira de compartilhar com seus compradores o valor superior que cria para eles (Forbis e Metha, 1981; Hanan, 1985; veja também Jackson, 1985).

Passamos agora a examinar as características comportamentais e as políticas administrativas das empresas orientadas para o mercado.

\section{Conteúdo da orientação para 0 mercado}

Para desenvolver uma hipótese acerca do conteúdo da orientação para o mercado a ser testada para determi- 
nar a validade do construto, começamos por rever o que há de mais relevante na literatura conceitual tanto sobre o VCS quanto sobre a orientação para o mercado, para identificar os principais pontos em comum (por exemplo, Aaker, 1988; Anderson, 1982; Day, 1984; Kotler, 1977; Levitt, 1960, 1980; Ohmae, 1982; Peters e Waterman, 1982; Porter, 1980, 1985). Inferimos da literatura que a orientação para o mercado considera três componentes comportamentais - orientação para o cliente, orientação para o concorrente e coordenação interfuncional - e dois critérios de decisão: enfoque de longo prazo e lucratividade.

A orientação para o cliente e a orientação para o concorrente incluem todas as atividades envolvidas na aquisição de informações sobre compradores e concorrentes no mercado-alvo e sua disseminação pela(s) empresa(s). O terceiro componente comportamental hipotético, a coordenação interfuncional, se baseia nas informações sobre clientes e competidores e compreende os esforços coordenados da empresa, geralmente envolvendo mais do que apenas o departamento de marketing, para criar superioridade no valor para o cliente. Em suma, os três componentes comportamentais hipotéticos da orientação para o mercado abrangem as atividades de aquisição e disseminação de informação sobre o mercado e a criação coordenada de valor para o cliente. Nossas inferências quanto ao conteúdo comportamental da orientação para o mercado condizem com as conclusões de Jaworski e Kohli (1993), que definem a orientação para o mercado como a geração e disseminação de informação na organização como um todo e uma resposta apropriada frente às necessidades e preferências atuais e futuras da clientela. Passamos agora a examinar mais detidamente os três componentes comportamentais e os dois critérios de tomada de decisão encontrados na orientação para o mercado.

Especificamente, a orientação para o cliente é a compreensão suficiente dos compradores visados para poder criar-lhes continuamente valor superior, ou, conforme Levitt (1980), criar-lhes continuamente um "produto ampliado". A orientação para o cliente exige que o vendedor compreenda toda a cadeia de valor do cliente (Day e Wensley 1988), não apenas tal como se encontra, mas também como irá se desenvolver com o passar do tempo, ao sabor da dinâmica interna e de mercado.

Há apenas duas maneiras de um vendedor criar valor: aumentando o benefício para o comprador em relação aos custos incorridos, e diminuindo os custos do comprador em relação aos benefícios auferidos. O vendedor deve compreender não só a dinâmica de cus- to e receita de seus compradores imediatos, mas também a dinâmica enfrentada pelos compradores de seus compradores, de onde deriva a demanda no mercado imediato. Assim, o vendedor precisa entender as restrições econômicas e políticas em todos os níveis do canal. Apenas armado de um arcabouço assim abrangente é que o vendedor poderá entender quem são seus atuais clientes potenciais e quem poderão vir a ser no futuro; o que desejam hoje e o que desejarão no futuro; e sua percepção atual e a percepção que terão no futuro daquilo que satisfaz seus desejos.

A orientação para o concorrente significa a compreensão, por parte do vendedor, dos pontos fortes e fracos de curto prazo, e das capacidades e estratégias de longo prazo, tanto dos principais concorrentes atuais como dos potenciais (Aaker, 1988; Day e Wensley, 1988; Porter, 1980, 1985). Paralelamente à análise dos clientes, a análise dos principais concorrentes atuais e potenciais deve incluir todo o conjunto de tecnologias capazes de atender às necessidades atuais e projetadas dos compradores visados pelo vendedor (Levitt, 1960).

O último dos três componentes comportamentais é a coordenação interfuncional, a utilização coordenada dos recursos da empresa para criar valor superior para os clientes-alvos. Qualquer ponto da cadeia de valor do comprador pode representar uma oportunidade para que o vendedor crie valor para a empresa compradora. Assim sendo, qualquer pessoa em qualquer cargo de uma empresa vendedora tem o potencial para contribuir para a criação de valor para o cliente (Porter, 1985). Criar valor para o cliente é muito mais do que uma mera "função de marketing": a criação de valor para o cliente é análoga a uma orquestra sinfônica em que a contribuição de cada subgrupo é ajustada e integrada por um maestro, resultando num efeito sinérgico. O vendedor precisa utilizar e integrar com eficácia seus recursos humanos e de capital, e adaptálos na medida do necessário, para criar valor superior para seus compradores. Assim, tal esforço é o ponto focal da empresa como um todo e não de um único departamento (por exemplo, Webster, 1988).

A integração coordenada dos recursos da empresa na criação de valor superior para os compradores está, é claro, intimamente associada à orientação tanto para o cliente quanto para a competição. Dada a natureza multidimensional da criação de valor superior para a clientela, a interdependência do marketing com outras funções deve ser sistematicamente incorporada à estratégia de marketing das empresas (Wind e Robertson, 1983). 
Quando uma empresa carece de tradição de coordenação multifuncional, é preciso que haja patrocínio e liderança eficazes para superar o isolamento entre cada área funcional e as demais funções. Atingir uma coordenação interfuncional eficaz exige, entre outras coisas, um alinhamento entre os incentivos da área funcional e a criação de dependência interfuncional, de tal maneira que cada área perceba haver vantagem em cooperar com as demais. Se uma empresa recompensar cada área funcional pela contribuição dada à criação de valor superior para o cliente, o auto-interesse levará as áreas a uma participação plena (por exemplo, Ruekert e Walker, 1987a, 1987b; Wind e Robertson, 1983). No desenvolvimento de uma coordenação interfuncional eficaz, o marketing e quaisquer outros departamentos patrocinadores devem ser extremamente sensíveis e reativos às percepções e necessidades de todos os demais departamentos da empresa (por exemplo, Anderson, 1982).

A literatura sugere que numa orientação para o mercado predomine um foco de longo prazo tanto sobre os lucros (por exemplo, Felton, 1959) quanto sobre a implementação de cada um dos três componentes comportamentais da orientação para o mercado (por exemplo, Houston, 1986; Jaworski e Kohli, 1993). Para sobreviver a longo prazo frente à competição, a empresa não pode evitar uma perspectiva de longo prazo. Para impedir que os concorrentes esvaziem as superioridades obtidas em valor para o cliente, a empresa precisa descobrir e implementar constantemente valor adicional para o cliente, o que exige uma ampla gama de táticas e investimentos voltados para isso. Anderson (1982) dá ênfase ao fato de que a orientação para o mercado traz implicitamente uma perspectiva de longo prazo.

Finalmente, a literatura sugere que o objetivo primordial das empresas na orientação para o mercado seja a lucratividade (ou a riqueza econômica) (por exemplo, Felton, 1959; McNamara, 1972). Na revisão que fizeram da literatura, Jaworski e Kohli (1993) concluíram, como nós, que os lucros são percebidos como um dos componentes da orientação para o mercado. Mas seus dados obtidos no campo revelaram que a lucratividade é vista como uma consequêencia da orientação para o mercado. Adotamos uma posição intermediária, sustentando que a lucratividade, embora conceitualmente próxima da orientação para o mercado, é mais apropriadamente tida como um objetivo empresarial. Assim, separamos tanto a lucratividade quanto o foco de longo prazo daquilo que considera- mos os três componentes comportamentais da orientação para o mercado. Para organizações sem fins lucrativos, o objetivo análogo à lucratividade é a sobrevivência, o que significa obter receitas suficientes para enfrentar as despesas de longo prazo e/ou satisfazer a longo prazo os principais constituintes (por exemplo, Kotler e Andreasen, 1987).

Voltamo-nos, agora, para o desenvolvimento de uma medida válida de orientação para o mercado. Primeiramente, formulamos uma hipótese sobre seu conteúdo, para em seguida discutirmos as análises de confiabilidade e validade durante o desenvolvimento da validade do construto.

\section{DESENVOLVIMENTO DE UMA MEDIDA VÁLIDA DE ORIENTAÇÃO PARA O MERCADO}

\section{Hipótese acerca do conteúdo da orientação para 0 mercado}

Formulamos a hipótese de que a orientação para o mercado seja um construto unidimensional consistente formado por três componentes comportamentais e dois critérios decisórios: orientação para o cliente, orientação para o concorrente, coordenação interfuncional, foco de longo prazo e objetivo de lucro, onde cada um dos cinco componentes do construto pode ser medido de forma confiável por meio de uma escala com múltiplos itens.

Formulamos a hipótese de um construto unidimensional porque, conceitualmente, os três componentes comportamentais e os dois critérios de tomada de decisão são fortemente relacionados. Para um negócio maximizar seus lucros de longo prazo, deve continuamente criar valor superior para seus clientes-alvos. Para tanto, a empresa precisa voltar-se para eles e para os competidores, e ser interfuncionalmente coordenada. Com base na revisão da literatura, inferimos que os três componentes comportamentais têm igual importância média. Assim, a orientação para o mercado é representada na Figura 1 como um triângulo eqüilátero.

\section{Validade aparente}

Para estabelecer a validade aparente do construto, desenvolvemos uma variedade de itens que caracteriza os cinco componentes hipotéticos da orientação para o mercado. Em seguida, submetemos esses itens a um painel de três acadêmicos notoriamente conhecidos como autoridades em marketing estratégico. Esses acadêmicos classificaram cada um dos itens em temos de consistência com a orientação para o mercado e reco- 
mendaram a inclusão de novos itens. Submetemos os itens que receberam classificação elevada ou foram sugeridos por um membro do primeiro painel a um segundo painel de três acadêmicos, igualmente reconhecidos como autoridades em marketing estratégico. Foram incluídos no instrumento os itens que, na opinião do segundo painel, apresentaram elevada consistência com a orientação para o mercado.

Os itens foram redigidos de maneira a refletir práticas favoráveis e desfavoráveis para contrabalançar qualquer viés afirmativo/negativo. As respostas foram registradas numa escala Likert de 7 pontos, em que 1 indicava que a unidade de negócio não apresentava nenhuma prática e 7 indicava que as práticas eram intensamente adotadas.

O questionário preliminar foi objeto de pré-teste com seis atuais ou ex-gestores de unidades estratégicas de negócio (UENs) do grupo de onde retiraríamos nossa amostra. Ao instruir esses seis administradores, obtivemos sua impressão acerca da ambigüidade e interpretação dos itens selecionados e da probabilidade de que algumas das afirmativas pudessem induzir respostas social ou profissionalmente desejáveis. Com base em seus comentários, ajustamos alguns dos itens e redigimos o instrumento definitivo.

Figura 1 - Orientação para o mercado.

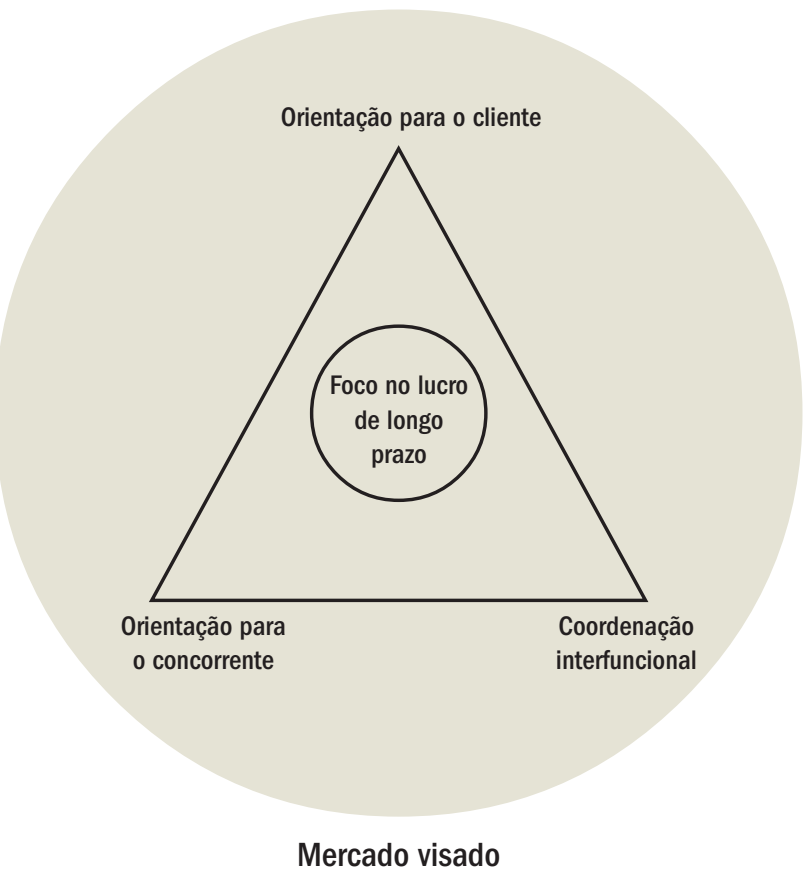

\section{Amostra}

As unidades de amostragem do estudo são 140 unidades estratégicas de negócio (UENs) de um grande grupo do oeste dos Estados Unidos. Define-se UEN como uma unidade organizacional com estratégia de negócio definida e dotada de um gestor com responsabilidade sobre vendas e lucros (Aaker, 1988). Dentro de cada UEN, a equipe de alta administração foi identificada pelo executivo responsável do grupo. Cada membro da alta administração recebeu um questionário intitulado "Pesquisa de práticas de negócios", com perguntas sobre práticas e estratégias competitivas, ambiente competitivo e desempenho da UEN em seu principal mercado. Garantimos anonimato aos respondentes. Também usamos um sistema de codificação que impedia que nós ou os administradores da empresa pudéssemos identificar individualmente qualquer um dos respondentes. Heneman (1974) demonstrou que a chance de obter respostas livres de viés é maior quando os pesquisados têm anonimato assegurado.

Foram enviados 440 questionários. Desses, foram devolvidos 371 questionários utilizáveis, uma taxa de resposta de 84\%. Das 113 UENs (81\%) com dados completos, 36 estavam no setor de commodities, 23 em produtos especializados, 51 em distribuição e três em exportação. Essas atividades são descritas como se segue: 1. As empresas do setor de commodities vendem produtos físicos como madeira por volume ou área, compensado, lascas de madeira e madeira em troncos, todos essencialmente idênticos em qualidade e desempenho aos da concorrência. Ao tentar criar valor superior para os compradores, tais empresas normalmente são incapazes de adaptar seu "produto genérico" (Levitt, 1980). Como compensação, precisam acrescentar diversos benefícios a seus produtos genéricos e/ou reduzir os custos não repassáveis dos compradores. Os clientes das unidades de commodities são os distribuidores atacadistas do grupo e varejistas externos, tanto nacionais quanto estrangeiros.

2. As empresas fora do setor de commodities são aquelas que, ao tentar criar valor superior para o cliente, podem tanto adaptar seus produtos (ou serviços) genéricos quanto acrescentar benefícios a esses produtos e/ ou reduzir o custo não repassável dos compradores. Há na amostra dois tipos de unidades fora do setor de commodities:

- Unidades de produtos especializados. Alguns exemplos de produtos das unidades especializadas são armários de compensado, portas laminadas, placas de fibra, placas de aglomerado e sistemas de susten- 
tação de telhados. Os clientes são varejistas nacionais, refabricantes do setor de construção, fabricantes de móveis e os próprios distribuidores atacadistas do grupo.

- Unidades de distribuição. Essas unidades atacadistas do grupo compram principalmente de outras unidades do mesmo grupo e revendem a varejistas de materiais de construção, empreiteiras e exportadoras.

\section{Análise de confiabilidade}

Dividimos os dados aleatoriamente em duas amostras antes de avaliar a confiabilidade e a validade (Churchill, 1979). Realizamos análises de confiabilidade com a primeira amostra e depois as replicamos com a segunda, passando em seguida a testes de validade do construto para as amostras combinadas.

Os valores de confiabilidade da escala (coeficiente $\alpha$ ) e as correlações entre os itens e o total constam da Tabela 1. A confiabilidade da orientação para o cliente, da orientação para o concorrente e da coordenação interfuncional superam 0,7 , o limite que Nunnally (1978, p. 245) recomenda para pesquisas exploratórias. Mas as medidas de orientação para o longo prazo e de lucro como objetivo não atendem a esse critério, talvez porque os itens sejam insuficientes ou inadequados. Devido à baixa pontuação de confiabilidade, não podemos extrair conclusões sobre a relação empírica entre os dois critérios decisórios e os três componentes comportamentais da orientação para o mercado. Se os dois critérios decisórios são na verdade dois componentes de um construto unidimensional, dois componentes de uma segunda dimensão ou alguma outra coisa é uma pergunta importante, mas que devemos deixar para pesquisas futuras (veja a seção "Limitações e implicações para pesquisas futuras"). Na discussão que se segue a respeito dos testes de validade do construto, examinamos apenas os três componentes comportamentais da orientação para o mercado: orientação para o cliente, orientação para o concorrente e coordenação interfuncional.

Dada a importância conceitual dos três componentes, a orientação de uma empresa para o mercado é a média aritmética dos pontos obtidos nos três componentes. A variável de desempenho em nossa análise é o retorno sobre ativos (ROA) da empresa em seu principal segmento de mercado durante o ano anterior comparado aos ROAs de todos os demais competidores.

Para os três componentes, assim como para orientação para o mercado e o ROA, a confiabilidade interrespondente é satisfatória (mede-se a confiabilidade inter-respondente pelo desvio padrão médio de cada equipe de alta administração, indicando a medida da dispersão das respostas). Para todas as empresas da amostra, os desvios padrão médios das equipes de alta administração (escala de 7 pontos) foram: orientação para o cliente 0,360 ; orientação para o concorrente 0,402 ; coordenação interfuncional 0,321 ; orientação para o mercado 0,280; e ROA 0,705.

\section{Validade do construto}

Há evidência de validade do construto quando o padrão de correlação entre as variáveis condiz com o que prevê a teoria (Cronbach, 1970, p. 143; Kerlinger, 1973, p. 463). Examinamos, por meio de correlação simples e análise fatorial, as relações entre os três componentes comportamentais centrais da orientação para o mercado e três outras variáveis de política administrativa conceitualmente ligadas à orientação para o mercado. Essas variáveis de política administrativa são: política de administração de recursos humanos, vantagem competitiva baseada em diferenciação e vantagem competitiva baseada em baixo custo. Os itens dessas escalas e os valores de confiabilidade de cada item com relação à totalidade das correlações estão na Tabela 2.

Oferecemos três proposições acerca das relações teóricas entre as variáveis. Essas proposições se referem, respectivamente, a validade convergente, validade discriminante e validade concorrente. Cada uma delas está implícita na discussão teórica acima.

$\mathrm{P}_{1}$ : Validade convergente. Há uma forte correlação entre os três componentes da orientação para o mercado.

Uma forte correlação entre os três componentes da orientação para o mercado indica que eles são convergentes sobre um construto comum, fornecendo, assim, evidência de validade convergente. Todas as correlações superam 0,67 e todas são significativas a p $<0,001$ (veja a Tabela 3). A validade convergente também é sugerida pelo elevado alfa de Cronbach $(0,8810)$, obtido quando as pontuações das três escalas são combinadas numa só escala; e pela elevada solução unifatorial, obtida numa análise fatorial exploratória (eigenvalue $=7,1,44,8 \%$ da variância explicada).

$\mathrm{P}_{2}$ : Validade discriminante. A correlação entre a coordenação interfuncional e política da administração de recursos humanos é substancialmente inferior às correlações entre coordenação interfuncional e os demais componentes de orientação para o mercado. 
Para avaliar a validade discriminante, incluímos no questionário uma escala para medir a política de gestão de recursos humanos (Hitt e Ireland, 1986). Essa escala foi desenvolvida para avaliar a importância que uma organização empresarial atribui a políticas e atividades de recrutamento, motivação e recompensa de empregados. A política de gestão de recursos humanos e a coordenação interfuncional são ambas políticas de "gestão de pessoas". Para se afirmar que orientação para o cliente, orientação para o concorrente e coordenação interfuncional medem uma orientação geral para o mercado, e não algo genérico que descreva uma boa gestão, a correlação entre política de gestão de recursos humanos e coordena- ção interfuncional deve ser substancialmente inferior à correlação existente entre coordenação interfuncional, orientação para o cliente ou orientação para o concorrente.

Os resultados do teste quanto a diferenças significativas entre as correlações dependentes (Cohen e Cohen, 1975, p. 53), encontrados na Tabela 4, demonstram que a correlação entre política de gestão de recursos humanos e coordenação interfuncional é significativamente inferior às correlações entre a coordenação interfuncional e os demais componentes da orientação para o mercado. Esses resultados dão respaldo à validade discriminante do construto de orientação para o mercado em três componentes.

Tabela 1 - Análise de confiabilidade.

\begin{tabular}{|c|c|c|c|}
\hline \multirow[b]{2}{*}{ ITEM } & \multicolumn{2}{|c|}{ AMOSTRA $1(N=190)$} & \multirow{2}{*}{$\begin{array}{c}\text { AMOSTRA } 2(\mathrm{~N}=175) \\
\text { ALFA DE } \\
\text { CRONBACH }\end{array}$} \\
\hline & $\begin{array}{c}\text { ALFA DE } \\
\text { CRONBACH }\end{array}$ & $\begin{array}{l}\text { CORRELAÇÃO } \\
\text { ITEM-TOTAL }\end{array}$ & \\
\hline Orientação para 0 cliente & 0,8547 & & 0,8675 \\
\hline Compromisso com o cliente & & 0,7021 & \\
\hline Criação de valor para o cliente & & 0,6580 & \\
\hline Compreensão das necessidades do cliente & & 0,6717 & \\
\hline Objetivos de satisfação do cliente & & 0,6517 & \\
\hline Mensuração da satisfação do cliente & & 0,6342 & \\
\hline Atendimento pós-venda & & 0,5794 & \\
\hline Orientação para o concorrente & 0,7164 & & 0,7271 \\
\hline Vendedores compartilham informações sobre concorrentes & & 0,5466 & \\
\hline Reação rápida a ações dos concorrentes & & 0,5908 & \\
\hline A alta administração discute as estratégias dos concorrentes & & 0,5421 & \\
\hline Visar oportunidades de vantagem competitiva & & 0,3612 & \\
\hline Coordenação interfuncional & 0,7112 & & 0,7348 \\
\hline Chamadas interfuncionais a clientes & & 0,4090 & \\
\hline Compartilhamento de informações entre funções & & 0,4775 & \\
\hline Integração funcional é parte da estratégia & & 0,6618 & \\
\hline Todas as funções contribuem para o valor para o cliente & & 0,5060 & \\
\hline Compartilhamento de recursos com outras unidades de negócio & & 0,3171 & \\
\hline Horizonte de longo prazo & 0,4775 & & 0,4080 \\
\hline 0 principal objetivo são os lucros trimestrais & & 0,3382 & \\
\hline Exige-se retorno rápido & & 0,3020 & \\
\hline Margem positiva no longo prazo & & 0,2613 & \\
\hline Ênfase no lucro & 0,1398 & & 0,0038 \\
\hline Desempenho de lucro medido mercado-a-mercado & & 0,1021 & \\
\hline A alta administração enfatiza o desempenho de mercado & & 0,1366 & \\
\hline Todos os produtos devem ser lucrativos & & $-0,3463$ & \\
\hline
\end{tabular}


$\mathrm{P}_{3}$ : Validade concorrente. As correlações entre os componentes de orientação para o mercado e a estratégia de diferenciação superam suas correlações com a estratégia de baixo custo.

Porter (1980) caracteriza as fontes de vantagem competitiva como baixo custo ou diferenciação. Na práti- ca, a qualquer tempo, as empresas podem dar ênfase a qualquer uma delas ou a ambas (Hall, 1980). Segundo a concepção de Porter (1980, p. 37), as abordagens à diferenciação (que interpretamos como benefícios adicionais do "produto") podem assumir diversas formas, inclusive imagem da marca, características do produto, atendimento ao cliente, rede de distribuição e tec-

Tabela 2 - Descrições das escalas das variáveis de política administrativa.

\begin{tabular}{|l|c|c|}
\hline \multicolumn{1}{|c|}{ ITEM } & \multicolumn{2}{c|}{ TOTAL DA AMOSTRA } \\
\hline \multicolumn{1}{|c|}{} & $\begin{array}{c}\text { ALFA DE } \\
\text { CRONBACH }\end{array}$ & $\begin{array}{c}\text { CORRELAÇÃO } \\
\text { ITEM-TOTAL }\end{array}$ \\
\hline Gestão de recursos humanos & 0,8122 & 0,6034 \\
\hline Políticas de pessoal eficazes & & 0,5029 \\
\hline Otimização do giro & & 0,6774 \\
\hline Melhora de atitudes & & 0,5164 \\
\hline Recompensa da criatividade & & 0,5366 \\
\hline Procedimentos de reclamação eficazes & & 0,6332 \\
\hline Estímulo à educação dos empregados & 0,8259 \\
\hline Vantagem competitiva baseada em diferenciação & & 0,7203 \\
\hline Introdução de novos produtos & & 0,6665 \\
\hline Diferenciação dos produtos & & 0,6022 \\
\hline Oferta de linha de produto ampla & & 0,6181 \\
\hline Uso de pesquisa de marketing & & \\
\hline Vantagem competitiva baseada em baixo custo & 0,7624 & 0,5636 \\
\hline Menores custos de fabricação & & 0,4301 \\
\hline Modernização da fabricação & & 0,5100 \\
\hline Melhoria do layout da linha & & 0,6352 \\
\hline Maior utilização da capacidade & & 0,4632 \\
\hline Realização de análises de valor das matérias-primas & \\
\hline Melhor acesso a matérias-primas & & 0,4817 \\
\hline
\end{tabular}

Tabela 3 - Análise de correlação: escalas de orientação para o mercado, política administrativa e ROA.

\begin{tabular}{|l|c|c|c|c|c|c|c|c|}
\hline & CUSTO & COMPO & COORD & ORMER & ARH & DIFE & BXCST & ROA \\
\hline CUSTO & - & & & & & & \\
\hline COMPO & $0,7353^{\mathrm{a}}$ & - & & & & & \\
\hline COORD & $0,7210^{\mathrm{a}}$ & $0,6564^{\mathrm{a}}$ & - & & & & \\
\hline ORMER & $0,9120^{\mathrm{a}}$ & $0,9047^{\mathrm{a}}$ & $0,8699^{\mathrm{a}}$ & - & & & \\
\hline ARH & $0,4366^{\mathrm{a}}$ & $0,2686^{\mathrm{b}}$ & $0,5308^{\mathrm{a}}$ & $0,4561^{\mathrm{a}}$ & - & & \\
\hline DIFE & $0,4424^{\mathrm{a}}$ & $0,4482^{\mathrm{a}}$ & $0,3261^{\mathrm{a}}$ & $0,4540^{\mathrm{a}}$ & $0,1630^{\mathrm{c}}$ & - & & \\
\hline BXCST & $0,2676^{\mathrm{b}}$ & $0,1766^{\mathrm{c}}$ & $0,3243^{\mathrm{a}}$ & $0,2767^{\mathrm{b}}$ & $0,5704^{\mathrm{a}}$ & $0,2276^{\mathrm{b}}$ & - & \\
\hline ROA & $0,3029^{\mathrm{a}}$ & $0,3892^{\mathrm{a}}$ & $0,2287^{\mathrm{b}}$ & $0,3454^{\mathrm{a}}$ & 0,3021 & $0,1677^{\mathrm{c}}$ & 0,0856 & - \\
\hline
\end{tabular}

a $p<0,001$

b $p<0,01$.

${ }^{c} p<0,05$. 
nologia. Esses efeitos de diferenciação são essencialmente externos - ou seja, cada uma é uma tentativa de deslocar para cima a curva de demanda da empresa. Por outro lado, uma vantagem de baixo custo que se refere às eficiências internas que podem ser repassadas aos compradores como menores custos de aquisição e uso - depende das economias de escala, escopo e volume que resultem em reduções de custos em atividades tais como $P \& D$, produção, atendimento, equipe de vendas e publicidade.

Parece razoável que uma estratégia de diferenciação, com sua ênfase externa, tenda mais a ser explorada por uma UEN com forte orientação para o mercado do que uma estratégia de baixo custo, que não dá, necessariamente, ênfase ao exterior. Uma maior correlação entre os três componentes da orientação para o mercado e a estratégia de diferenciação do que entre esses componentes e uma estratégia de baixo custo corroboraria a validade concorrente do construto de orientação para o mercado.

Estudos anteriores identificaram atividades associadas a estratégias de diferenciação e de baixo custo (Dess e Davis, 1984; Galbraith e Schendel, 1983). Com base nas atividades identificadas nesses estudos, desenvolvemos escalas para medir até que ponto essas duas estratégias são utilizadas. Pedimos aos respondentes que classificassem a importância das atividades competitivas numa escala Likert de 7 pontos. Os valores de confiabilidade das escalas superaram 0,75 , e sua intercorrelação foi de $0,304(p<0,001)$. A correlação da orientação para o mercado com a estratégia de diferenciação foi de 0,45 ; a correlação com a estratégia de baixo custo foi de 0,28 . A diferença entre as correlações é significativa a $\mathrm{p}<0,05$ (veja a Tabela 4). Os resultados dão respaldo à validade concorrente do construto de orientação para o mercado em três componentes.

Em suma, encontramos evidências de validade con- vergente, validade discriminante e validade concorrente e, com isso, apoio para a validade do construto do modelo de orientação para o mercado em três componentes. Passamos agora a examinar a relação do construto de orientação para o mercado em três componentes com o desempenho empresarial.

\section{EFEITO DA ORIENTAÇÃO PARA O MERCADO SOBRE $O$ DESEMPENHO EMPRESARIAL}

\section{Mensuração da orientação para 0 mercado e da lucratividade da empresa}

Como a teoria da orientação para o mercado sugere que os três componentes comportamentais sejam de igual importância, admitimos pesos iguais para os três. Assim, calculamos a pontuação de orientação para o mercado de uma UEN como a média aritmética das somas das pontuações atribuídas segundo as respostas dadas pela equipe de alta administração aos três componentes: orientação para o cliente, orientação para o concorrente e coordenação interfuncional.

A lucratividade de uma UEN é medida como a avaliação que a alta administração faz do retorno sobre ativos (ROA) da UEN em relação ao de todos os competidores no principal mercado atendido no ano anterior. Pedimos aos respondentes que considerassem rendimento do investimento, rendimento do ativo e rendimento ativo líquido como equivalentes, já que eles teriam que comparar a lucratividade da UEN com a de seus concorrentes no principal mercado atendido. O desempenho relativo foi usado para controlar diferenças de desempenho entre os mercados atendidos pelas UENs. Medidas subjetivas de desempenho são freqüentemente usadas em pesquisas sobre empresas de capital fechado e unidades de negócio de grandes companhias. Estudos anteriores identificaram uma

Tabela 4 - Teste-t de significância das diferenças entre coeficientes de variáveis dependentes.

\begin{tabular}{|c|c|c|c|}
\hline VARIÁVEL & $r$ & $t^{*}$ & p (uma cauda) \\
\hline ARH-COORD & 0,5308 & $\begin{array}{c}-1,749 \\
(n=126)\end{array}$ & $<0,05$ \\
\hline $\begin{array}{l}\text { COMPO-COORD } \\
\text { ARH-COORD }\end{array}$ & $\begin{array}{l}0,6564 \\
0,5308\end{array}$ & $\begin{array}{c}-3,045 \\
(n=125)\end{array}$ & $<0,005$ \\
\hline $\begin{array}{l}\text { CUSTO-COORD } \\
\text { DIFE-ORMER }\end{array}$ & $\begin{array}{l}0,7210 \\
0,4540\end{array}$ & $\begin{array}{c}1,790 \\
(n=123)\end{array}$ & $<0,05$ \\
\hline BXCST-ORMER & 0,2767 & & \\
\hline
\end{tabular}


forte correlação entre as avaliações subjetivas e suas correspondentes objetivas (por exemplo, Dess e Robinson, 1984; Pearce, Robbins e Robinson, 1987).

\section{Relações esperadas entre orientação para 0 mercado e lucratividade}

Formulamos a hipótese de que quanto maior a orientação para o mercado de uma empresa, maior será sua lucratividade em igualdade das demais condições. Mais especificamente, esperamos encontrar uma relação geral positiva entre orientação para o mercado e lucratividade da empresa nos três tipos de unidade de negócio constantes da amostra (commodity, distribuição e produtos especializados). Não esperamos encontrar a mesma forma de relação entre os três tipos de unidade de negócio.

Como veremos adiante, uma relação monotonicamente crescente entre orientação para o mercado e lucratividade é mais provável nas unidades de distribuição especializadas do que nas de commodities. De modo geral, implementar os três componentes da orientação para o mercado é mais fácil para aquelas. Esperamos, assim, que as unidades de distribuição e as especializadas sejam capazes de implementar a orientação para o mercado como um processo contínuo, atingindo ganhos aproximadamente proporcionais em ROA.

$\mathrm{Na}$ indústria de produtos florestais, os vendedores de commodities como madeira por área ou volume e compensado tradicionalmente criam valor para o cliente por meio da oferta de preços baixos para uma dada qualidade de produto. Os varejistas e outros compradores comerciais criaram o hábito de pesquisar cuidadosamente os diferentes vendedores para encontrar o melhor valor em termos de preço. Hoje, até certo ponto, a virtual totalidade das empresas de produtos florestais entende que pode criar valor superior para os compradores de commodities por outros meios e não apenas pelo preço. Ainda assim, variam muito quanto ao sucesso da implementação de estratégias de valor para o cliente que não sejam baseadas em preço.

Uma empresa que negocie com commodities, especialmente num setor tão tradicional como o de produtos florestais, pode manter uma perspectiva internamente orientada de si mesma, inclusive uma estratégia de marketing de "leilão de preços". Uma empresa de produtos florestais com uma orientação interna vêse como uma empresa que está "no negócio de vender madeira" e não no de "identificar e satisfazer as necessidades dos clientes". Determinadas políticas empresariais reforçam tal orientação interna e as concomitantes estratégias de preço.
Para vender seus produtos, algumas empresas de produtos florestais dependem primordialmente de sua equipe de vendas para visitar varejistas e outros clientes potenciais, ao passo que outras se fiam mais numa abordagem baseada num centro de vendas. Nesse caso, a maior parte do contato com clientes atuais e potenciais é feito por meio do telefone.

Evidentemente, uma empresa vendedora em qualquer setor que seja precisa manter uma compreensão profunda e atualizada das atividades dos compradores se quiser continuar a criar para eles valor superior, ou seja, precisa constantemente descobrir e implementar programas de melhoria de lucros para o cliente (por exemplo, Hanan, 1985). A maneira mais eficaz de descobrir oportunidades de ampliação do valor para o cliente é visitar freqüentemente as empresas compradoras e seus clientes.

Num setor de commodity é mais difícil criar valor para o cliente por meio de uma abordagem de telemarketing do que por outra que empregue uma equipe de vendas no campo. Isso se dá por dois motivos principais. Primeiro, é muito mais difícil para um vendedor identificar oportunidades de aumento de valor que o comprador ainda não imaginou se o contato se der por telefone. Um vendedor que somente descubra as necessidades do cliente depois que o próprio cliente as identifica, trabalha de forma mais reativa e, portanto, mais movida pelo preço para o comprador. O segundo motivo é que uma abordagem de venda pelo telefone pode aumentar a sensibilidade dos compradores ao preço. Pelo telefone é mais difícil transmitir a totalidade dos benefícios que o comprador tem a auferir do vendedor, o custo total da transação para o comprador e, portanto, o valor total do vendedor para o comprador. Um comprador que perca de vista o valor total do vendedor tenderá a dar atenção excessiva ao preço, isto é, a comparar os preços dos diferentes vendedores em vez do valor total que cada um deles representa para si.

Empresas de commodities que empreguem uma abordagem por telemarketing podem, por meio de um esforço de equipe cuidadosamente integrado, criar valor superior para seus clientes. Mas o telemarketing é um meio mais difícil para se realizar tal objetivo.

O negócio de commodities da empresa objeto do estudo usa uma abordagem de centro de vendas/telemarketing proporcionalmente mais intensa do que a de qualquer de suas principais concorrentes. Assim, com base no argumento acima e na igualdade das demais condições, as unidades de commodities estão em desvantagem com relação aos concorrentes no que se 
refere a criar valor para o cliente. Dentro da própria empresa, as unidades de commodities são menos eficazes na criação de valor superior para o cliente, em igualdade das demais condições, do que as especializadas e de distribuição (nenhuma das quais emprega uma abordagem de centro de vendas/telemarketing). Dada a distância entre a unidade de commodity da empresa objeto e seus clientes e dada sua estratégia de marketing necessariamente mais voltada para preço, esperamos que o aspecto commodity da empresa objeto obtenha menor pontuação média de orientação para o mercado e menor pontuação média em cada um dos componentes da orientação para o mercado do que as unidades especializadas ou de distribuição. Esperamos também que as unidades de commodities apresentem menor lucratividade relativa média do que as especializadas ou de distribuição. Os dados da Tabela 5 condizem com essas expectativas.

Dentre as unidades de commodities, esperamos que entre as que apresentam menores pontuações médias de orientação para o mercado estejam diversas das empresas de grande porte. Isso porque elas podem ter a percepção de que aumentar sua orientação para o mercado seria muito custoso e pouco atraente, pelo menos a curto prazo. Para aumentar sua orientação para o mercado, uma empresa de commodities, ou qualquer outra, precisa, a fim de criar valor para o cliente, adaptar de forma consistente e abrangente todos os seus sistemas, orientando-os ao cliente e à competição. Por causa de sua orientação interna tradicional, algumas das empresas de commodities provavelmente estão "presas no meio termo". Ou seja, tentarão hesitantemente implementar uma orientação para o mercado. Darão início a alguns dos passos necessários, mas não os tomarão com a medida ou a persistência sufi- cientes para criar uma cultura verdadeiramente diferente. Conseqüentemente, enviarão mensagens confusas tanto para dentro quanto para fora da unidade.

A implicação é que, para empresas de commodities, a relação entre orientação para o mercado e lucratividade pode muito bem ter a forma de um "U", com as empresas de baixa e elevada orientação para o mercado apresentando maior lucratividade do que as que estão na faixa intermediária. Mais especificamente, esperamos que a unidade de mais intensa orientação para o mercado tenha a maior lucratividade e que a de menor orientação para o mercado tenha a segunda maior lucratividade. A explicação para esse aparente paradoxo está no fato de que as empresas de menor orientação para o mercado, ou seja, as mais orientadas internamente, podem ser altamente consistentes e eficientes no que fazem. Com isso, podem conseguir, por meio de uma estratégia de baixo preço, atingir algum sucesso em termos de lucros, embora não tão marcante quanto o obtido por unidades de elevada orientação para o mercado. Para isolar o efeito da orientação para o mercado sobre a lucratividade empresarial, é preciso controlar os outros principais fatores que podem afetar a lucratividade, o que passamos a fazer em seguida.

\section{Controle de outras influências sobre a lucratividade da empresa}

A literatura sobre organização industrial e estratégia de marketing enfatiza consideravelmente oito variáveis conjunturais que podem afetar a lucratividade (veja, por exemplo, Aaker, 1988; Bain, 1959; Day, 1984; Scherer, 1980). Essas variáveis conjunturais precisam ser controladas quando se analisa o efeito da orientação para o mercado sobre a lucratividade empresarial.

As relações entre os elementos primários da teoria

Tabela 5 - Médias e faixas por tipo de unidade.

\begin{tabular}{|l|c|c|c|c|}
\hline & \multicolumn{3}{|c|}{ TIPO DE UNIDADE } & MÉDIA DAS UNIDADES \\
\cline { 2 - 5 } & COMMODITIES & ESPECIALIZADAS & DE DISTRIBUIÇÃO & DE NÃO COMMODITIES \\
\hline CUSTO & $4,53(2,8-5,8)$ & $5,50(3,7-6,0)$ & $4,99(3,4-6,1)$ & $5,01^{\mathrm{b}}$ \\
\hline COMPO & $4,06(2,8-5,3)$ & $5,71(3,3-5,8)$ & $4,92(3,4-6,6)$ & $4,85^{\mathrm{b}}$ \\
\hline COORD & $4,25(2,6-5,4)$ & $4,53(3,2-5,7)$ & $4,38(3,3-5,8)$ & $4,43^{\mathrm{c}}$ \\
\hline ORMER & $4,28(2,7-5,4)$ & $4,77(3,4-5,7)$ & $4,76(3,4-6,0)$ & $4,76^{\mathrm{b}}$ \\
\hline ROA & $4,00(1-6,5)$ & $4,65(1-7)$ & $4,71(1-7)$ & $4,69^{\mathrm{b}}$ \\
\hline
\end{tabular}

${ }^{a}$ Combinação das unidades especializadas e de distribuição. 0 valor $p$ se baseia no teste- $t$ das diferenças entre as médias das unidades de commodities e não commodities.

${ }^{\mathrm{b}} \mathrm{p}<0,01$.

${ }^{c} p<0,10$. 
da orientação para o mercado - os componentes de orientação para o mercado, as variáveis no nível do negócio e no nível do mercado e o desempenho - constam do modelo de efeitos independentes (Boal e Bryson, 1987) apresentado na Figura 2. A primeira variável de controle é o poder do comprador (Porter, 1980; Scherer, 1980). O poder do comprador é o grau em que um comprador pode negociar com seu fornecedor menores preços ou, mais genericamente, maior valor. O ponto de vista tradicional é que compradores e vendedores são "oponentes" e cada um procura extrair do outro a máxima contribuição para seu próprio lucro. Assim, adotando a perspectiva tradicional e mantendo iguais as demais condições, formulamos a hipótese de relação negativa entre o poder do comprador e a lucratividade da empresa.

O poder do fornecedor (Porter, 1980; Scherer, 1980) é a segunda variável de controle. Trata-se da medida em que um fornecedor pode negociar com seu comprador maiores preços ou, mais genericamente, maior valor. Adotando a perspectiva tradicional de que compradores e vendedores são oponentes e de que todo vendedor deseja extrair de cada comprador a máxima contribuição para seu próprio lucro, formulamos a hipótese de relação negativa entre o poder dos fornecedores e a lucratividade da empresa.
A terceira variável de controle é a concentração de vendedores (Bain, 1959; Scherer, 1980). Concentração de vendedores é o grau em que as vendas num mercado se concentram nas quatro ou oito empresas com maiores vendas. São sugeridos dois motivos independentes entre si pelos quais a concentração de vendedores, especialmente em níveis elevados, pode estar associada à alta lucratividade. O primeiro é que uma forte concentração de vendedores pode incentivar um comportamento monopolista tácito ou explícito. Uma empresa que não esteja entre os quatro maiores vendedores pode se beneficiar do "guardachuva de lucro" que se criará se os quatro se comportarem de acordo com essa primeira explicação (Demsetz, 1974). O segundo motivo é que uma elevada concentração de vendedores fará com que as empresas com maiores vendas captem significativas economias de escala e de volume. Desse ponto de vista, a concentração de vendedores implica benefícios para uma empresa apenas se ela estiver entre os quatro maiores vendedores (uma premissa correta para as unidades da nossa amostra). Implicando uma dessas explicações ou ambas, formulamos a hipótese de relação positiva entre concentração de vendedores e lucratividade.

Figura 2 - Modelo de efeitos independentes das relações entre orientação para o mercado, fatores específicos da unidade, fatores no nível do mercado e desempenho.

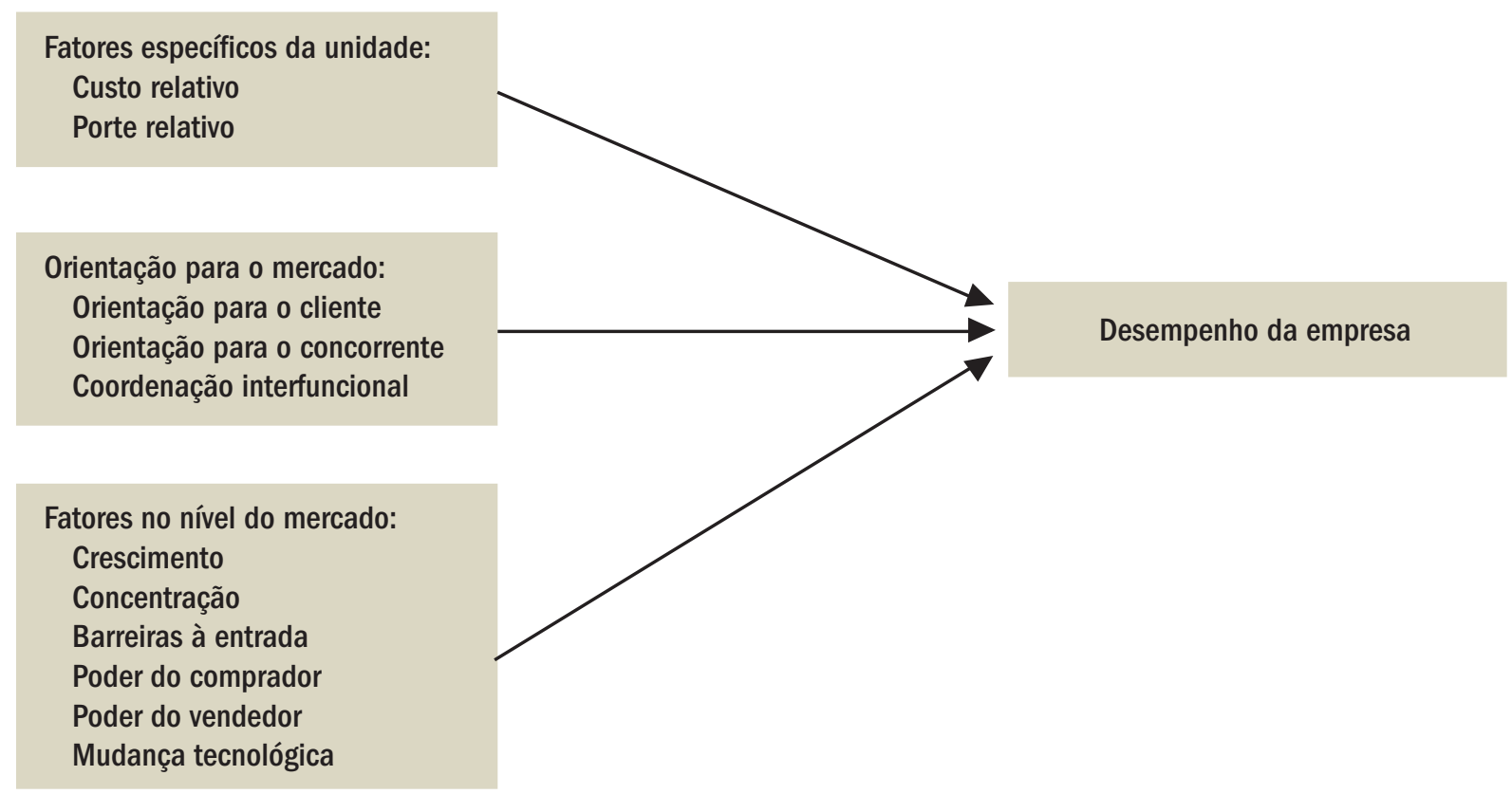


A facilidade de entrada de novos concorrentes (novos vendedores) no mercado é a quarta variável de controle (Bain, 1959; Porter, 1980; Scherer, 1980). Define-se facilidade de entrada como o custo incremental não repetitivo necessário para que uma empresa entre no mercado e se torne competitivamente viável. Quanto maior a facilidade de entrada, maior a pressão competitiva tanto dos competidores atuais quanto dos potenciais. Formulamos a hipótese de relação negativa entre facilidade de entrada e lucratividade do negócio.

A taxa de crescimento do mercado é a quinta variável de controle (Scherer, 1980). Em princípio, quando a demanda é crescente num mercado, fica mais fácil para todos os vendedores adquirir e manter clientes e obter lucros. Mas há quatro motivos para uma empresa não lucrar com o crescimento de curto prazo da demanda. O primeiro é que parte da variação de demanda a curto prazo é imprevista, e a empresa pode estar despreparada para reagir. O segundo é que uma parte considerável da capacidade de produção e marketing de uma empresa a curto prazo pode ser fixa em termos de qualidade e quantidade, e, portanto, os ajustes a variações da demanda serão lentos. O terceiro é que, havendo facilidade de entrada de novos vendedores, novos concorrentes virão com facilidade quando a demanda aumentar, captando parte dos lucros e levando a lucratividade a níveis negativos. Se também forem baixas as barreiras à saída, os novos competidores irão embora quando a demanda do mercado diminuir, retornando apenas quando surgir o próximo aumento de demanda. O quarto motivo é que uma empresa pode optar por "captar" seus ganhos decorrentes de aumentos de curto prazo da demanda sob a forma de maiores vendas aos mesmos preços. Dessa forma, aumenta-se o ROA de curto prazo, mas ainda se obtém lucro menor do que o propiciado pelo aumento dos preços, aproveitando-se do crescimento da demanda. Evidentemente, a relação entre crescimento de curto prazo da demanda do mercado e ROA é uma conjectura. Mas adotaremos a convenção e formularemos a hipótese de relação positiva entre crescimento do mercado e lucratividade.

A taxa de mudança da tecnologia é a sexta variável de controle (Scherer, 1980). Quanto maior a mudança de tecnologia num mercado, mais diversas serão as oportunidades de criar valor para o cliente. Mas o investimento necessário para ter sucesso com P\&D (Pesquisa e Desenvolvimento) e com a implementação de novas tecnologias pode ser substancial e, a curto prazo, pro- duzir lucros negativos. Esperamos que o segundo fator sobrepuje o primeiro a curto prazo e, portanto, formulamos a hipótese de uma relação negativa entre mudança tecnológica de curto prazo e lucratividade.

A sétima variável de controle é o tamanho da empresa em relação à sua maior concorrente no mercado (Scherer, 1980). Essa variável implica as vantagens associadas a uma maior participação relativa no mercado. A variável de porte relativo tem potencial para captar alguns dos efeitos tanto de receita quanto de custo. Formulamos a hipótese de relação positiva entre a vantagem de porte relativo de uma empresa e a lucratividade.

O custo operacional médio total da empresa em relação ao de sua maior concorrente é a oitava variável de controle (Scherer, 1980). Ao contrário da variável de porte relativo, a de custo relativo capta apenas efeito de vantagem de custo. A variável mede a diferença entre a média de todos os custos operacionais. Dessa forma, formulamos a hipótese de relação positiva entre a vantagem de custo e a lucratividade do negócio.

\section{Modelo empírico}

As variáveis foram medidas em escalas Likert de $7 \mathrm{ou}$ 8 pontos e definidas como a seguir.

\section{Variável dependente}

Retorno sobre ativos (ROA) relativo. O ROA de uma UEN no principal segmento de mercado atendido no ano anterior em relação aos ROAs de todos os demais competidores.

\section{Variáveis independentes}

1. Orientação para o mercado (OMER). A média aritmética das pontuações de uma UEN em orientação o para o cliente, orientação para o concorrente e coordenação interfuncional. Sinal esperado: positivo (+).

2. Quadrado da orientação para o mercado (QDOMER). O quadrado da pontuação de orientação para o mercado de uma UEN. Para testar a não-linearidade da relação orientação para o mercado-ROA entre as unidades de commodities. Sinal esperado: positivo $(+)$.

3. Poder do comprador (PDC). Em que medida os clientes de uma UEN são capazes de negociar menores preços. Sinal esperado: negativo (-).

4. Poder do fornecedor: (PDF). Em que medida uma UEN é capaz de negociar menores preços com seus fornecedores. Sinal esperado: positivo (+).

5. Concentração de vendedores (CDV). No principal segmento de mercado atendido por uma UEN, a porcenta- 
gem do total de vendas por que respondem os quatro competidores com maiores vendas (inclusive a UEN, quando apropriado). Sinal esperado: positivo (+).

6. Facilidade de entrada (ENTR). A probabilidade de que um novo competidor seja capaz de obter lucros satisfatórios no principal segmento de mercado atendido por uma UEN dentro de três anos a contar de sua entrada. Sinal esperado: negativo (-).

7. Crescimento do mercado (CRM). O crescimento médio anual do total de vendas no principal segmento de mercado atendido por uma UEN nos últimos três anos. Sinal esperado: positivo (+).

8. Mudança tecnológica (MTEC). Uma medida do quanto mudou a tecnologia de serviço/produção do principal segmento atendido por uma UEN nos últimos três anos. Sinal esperado: negativo (-).

9. Porte relativo (PORTR). O porte das receitas de vendas de uma UEN no principal segmento de mercado atendido em relação ao porte das receitas obtidas pelo maior competidor. Sinal esperado: positivo $(+)$.

10. Custo relativo (CUSTR). O custo operacional médio total (administrativo, de produção, marketing/vendas, etc.) de uma UEN em relação ao custo do maior competidor no principal segmento de mercado atendido. Sinal esperado: negativo (-).

\section{Resultados empíricos}

Usamos análise de regressão dos mínimos quadrados para testar a hipóteses de que a orientação para o mercado e o desempenho estão positivamente associados. ${ }^{1}$ A amostra de 110 UENs usada na análise de regressão consiste em 36 unidades de commodities, 23 de produtos especializados e 51 de distribuição. As unidades de produtos especializados e de distribuição foram combinadas numa única categoria chamada unidades de não commodities. Variáveis "simuladas" são usadas para controlar as diferenças entre as unidades de commodities e de não commodities. Empregamos variáveis simuladas numa única regressão por causa do pequeno porte da amostra de unidades de commodities. A Tabela 6 apresenta os resultados da regressão.

Na Tabela 6, onde há uma diferença estatisticamente significativa entre os coeficientes de regressão dos dois tipos de unidade, são mostrados os dois coeficientes. O coeficiente da orientação para o mercado é significativo para as unidades de não commodities ( $\mathrm{p} \leq$ 0,05), o que, como previa a hipótese, sugere relação não linear entre orientação para o mercado e ROA. A relação não linear é condizente com a expectativa de que as unidades de commodities com média orientação para o mercado teriam menor ROA do que as unidades de mínima ou máxima orientação para o mercado. Retornaremos a esse ponto em breve.

Os coeficientes de cinco das oito variáveis de controle são significativos a $\mathrm{p} \leq 0,05$ (calculamos o fator de inflação de variância, que não indicou problema de multicolinearidade entre as nove variáveis independentes). Os sinais dos coeficientes de crescimento do mercado e de poder do comprador foram o oposto do que previam as hipóteses. O sinal negativo do coeficiente de crescimento do mercado sugere que as UENs da amostra, por um ou mais motivos anteriormente propostos, obtiveram menores lucros do que seus concorrentes no que se refere à taxa trienal de crescimento do principal mercado atendido.

Para as unidades de commodities, o poder do comprador apresentou grande e significativo ( $\mathrm{p} \leq 0,01)$ coeficiente positivo. Esse resultando não condiz com a premissa convencional da literatura sobre organizações industriais (mas está de acordo com a literatura

Tabela 6 - Efeito da orientação para o mercado sobre o ROA.

\begin{tabular}{|c|c|c|c|c|c|c|c|c|c|c|c|c|c|}
\hline & OMER & QDOMER & PRTR & ENTR & CUSTR & CDV & CRM & PDF & PDC & MTEC & CONST & N & $\mathrm{R}^{2}$ \\
\hline Sinal esperado & + & + & + & - & - & + & + & + & - & - & & & \\
\hline $\begin{array}{l}\text { Unidades de } \\
\text { commodities }\end{array}$ & $\begin{array}{l}-7,632^{b} \\
(3,390)\end{array}$ & $\begin{array}{c}0,856^{b} \\
(0,393)\end{array}$ & & & & & & & $\begin{array}{l}1,245^{a} \\
(0,273)\end{array}$ & & $\begin{array}{l}19,266^{a} \\
(7,251)\end{array}$ & & \\
\hline $\begin{array}{l}\text { Amostra } \\
\text { combinada }\end{array}$ & & - & $\begin{array}{l}0,192^{b} \\
(0,082)\end{array}$ & $\begin{array}{l}-0,035 \\
(0,132)\end{array}$ & $\begin{array}{l}-0,583^{a} \\
(0,114)\end{array}$ & $\begin{array}{c}0,030 \\
(0,119)\end{array}$ & $\begin{array}{l}0,305^{\mathrm{a}} \\
(0,086)\end{array}$ & $\begin{array}{c}0,110 \\
(0,149)\end{array}$ & & $\begin{array}{l}-0,280^{b} \\
(0,127)\end{array}$ & & 110 & 0,410 \\
\hline $\begin{array}{l}\text { Unidades de não } \\
\text { commodities }\end{array}$ & $\begin{array}{l}0,501^{b} \\
(0,223)\end{array}$ & & & & & & & & $\begin{array}{l}-0,104 \\
(0,206)\end{array}$ & & $\begin{array}{c}6,056^{a} \\
(1,808)\end{array}$ & & \\
\hline
\end{tabular}

Obs.: Coeficientes separados são apresentados quando há diferença significativa entre eles; desvios padrão entre parênteses.

a $p \leq 0,01$.

${ }^{\mathrm{b}} \mathrm{p} \leq 0,05$. 
de marketing) de que compradores e vendedores são "oponentes". Não é difícil explicar como o poder do comprador poderia aumentar o ROA das UENs de commodities. Muitas empresas que operam com commodities - mesmo as orientadas internamente - dão atenção às necessidades dos clientes quando eles são poderosos. O resultado é uma parceria lucrativa entre eficientes empresas de commodities e compradores poderosos. Essa explicação é consistente com a conclusão de Barrett (1986) de que a concentração de compradores é uma determinante importante da atenção dada pelo vendedor às necessidades de seus compradores.

Para melhor esclarecer a relação linear entre a orientação para o mercado e o ROA nas unidades de commodities, dividimos as unidades em três grupos com base na pontuação obtida de orientação para o mercado: baixa $(\mathrm{N}=15)$, média $(\mathrm{N}=14)$ e alta $(\mathrm{N}=16)$. A amostra de cada grupo é pequena demais para permitir uma análise de regressão múltipla. Experimentamos com uma análise fatorial de rotação oblíqua das variáveis independentes para reduzir o conjunto, mas não obtivemos convergência. Assim, classificamos as médias das variáveis dependentes e independentes dos três grupos de unidades de commodities e as testamos em busca de diferenças significativas. Os resultados podem ser encontrados na Tabela 7 .

Entre os três grupos de unidades de commodities, as diferenças quanto às pontuações médias gerais de orien- tação para o mercado e quanto às pontuações dos três componentes são significativas. Como era esperado, o grupo de elevada orientação para o mercado apresentou o maior ROA, com diferença significativa em relação ao grupo intermediário. A diferença entre o ROA do grupo mínimo e o do médio também foi significativa. Examinamos, ainda, a relação entre orientação para o mercado e outra variável dependente, a taxa de retenção de clientes, que mede o quanto uma UEN é bemsucedida na retenção de seus clientes se comparada ao principal concorrente no principal mercado atendido. A pontuação da taxa de retenção de clientes de cada UEN é a média das respostas dadas pela equipe de alta administração a esse item. Não surpreende que as unidades de mais elevada orientação para o mercado apresentem as mais altas taxas de retenção de clientes, significativamente maiores do que as apresentadas pelos grupos de unidades de baixa ou média orientação para o mercado. As unidades de menor orientação para o mercado apresentaram as menores taxas de retenção de clientes.

Os dados da Tabela 7 implicam que o grupo de elevada orientação para o mercado criou barreiras à entrada. Os dados sugerem também que esse grupo de empresas está sob excelente gestão, apresentando a pontuação mais elevada tanto em gestão de recursos humanos quando em consenso entre a equipe de alta administração (desvio padrão das pontuações atribuí-

Tabela 7 - Classificação das médias e teste-t das diferenças entre as médias das unidades de commodities (baixa, média e alta 0MER).

\begin{tabular}{|c|c|c|c|}
\hline VARIÁVEL & BAIXA OMER ( $\mathrm{N}=15)$ & MÉDIA OMER ( $N=14)$ & ALTA OMER $(\mathrm{N}=16)$ \\
\hline ROA & $2^{\mathrm{c}}$ (vs. média) & $3^{c}$ (vs. alta) & 1 \\
\hline OMER & $3^{b}$ & $2^{b}$ & $1^{\text {b }}$ (vs. baixa) \\
\hline CUSTO & $3^{b}$ & $2^{b}$ & $1^{\mathrm{b}}$ \\
\hline COMPO & $3^{b}$ & $2^{b}$ & $1^{\mathrm{b}}$ \\
\hline COORD & $3^{b}$ & $2^{b}$ & $1^{b}$ \\
\hline Porte absoluto & $1^{\mathrm{d}}$ & 3 & $2^{c}$ \\
\hline Facilidade de entrada & $1^{c}$ & 2 & $3^{d}$ \\
\hline Concentração em 4 empresas & 3 & $2^{(0,12)}$ & $1^{\mathrm{d}}$ \\
\hline Poder sobre o fornecedor & $1^{c}$ & 3 & 2 \\
\hline $\mathrm{ARH}$ & 3 & $2^{c}$ & $1^{\mathrm{c}}$ \\
\hline OMER (consenso da alta administração) & 2 & $3^{(0,15)}$ & 1 \\
\hline Taxa de retenção de clientes & 3 & $2^{c}$ & $1^{\mathrm{b}}$ \\
\hline Tempo médio dos altos administradores na UNE (anos) & 1 & 2 & $3^{c}$ \\
\hline
\end{tabular}


das pelos membros da equipe à orientação para o mercado). Ademais, as equipes de alta administração das unidades de elevada orientação para o mercado são as de menor longevidade. Pode-se inferir disso que talvez sejam as mais capazes e dispostas para enfrentar mudanças e, especialmente, para realizar as amplas mudanças necessárias para aumentar substancialmente a orientação para o mercado.

O grupo médio, "preso no meio", ocupa a posição intermediária em quase todos os casos. Uma exceção notável é a última colocação no consenso da equipe de alta administração quanto à orientação para o mercado. A diferença entre a pontuação do grupo médio nessa variável e a do grupo de alta orientação para o mercado, embora significativa apenas no nível de 0,15, oferece uma explicação possível para a baixa orientação para o mercado do grupo intermediário e, assim, para seu fraco desempenho. Além disso, o grupo intermediário parece consistir nas menores unidades, com menor poder sobre seus fornecedores.

Mencionamos anteriormente que as unidades de grande porte podem ser as menos dispostas ou capazes de adotar uma orientação para o mercado. De forma consistente com essa expectativa, as unidades de commodities do grupo de baixa orientação para o mercado são as maiores em porte absoluto. Sua falta de orientação para o mercado também pode se dever em parte à maior longevidade da alta administração. As equipes de alta administração do grupo de baixa orientação para o mercado têm o maior número médio de anos em suas UENs. Além disso, o grupo de baixa apresenta as menores pontuações em gestão de recursos humanos, com diferença significativa em relação ao grupo de elevada orientação para o mercado. A baixa pontuação de gestão de recursos humanos, associada à baixa pontuação de coordenação interfuncional (e das duas outras dimensões da orientação para o mercado) sugere que os talentos de gestão de recursos humanos do grupo de baixa talvez sejam inferiores aos disponíveis no grupo de alta. O grupo de baixa depara com a mais fácil entrada de novos competidores, uma condição que em grande parte pode ser devida à baixa orientação dessas unidades para o mercado.

Essas conclusões complementam os resultados da análise de regressão, mais especificamente os de que a orientação para o mercado está fortemente relacionada à lucratividade tanto entre as unidades de commodities quanto entre as de não commodities. Os dados implicam que as unidades de commodities com maior orientação para o mercado têm substancial controle sobre seus mercados, como, por exemplo, sucesso na retenção de clientes e na criação de barreiras à entrada. As conclusões sugerem também que as unidades de commodities nos diversos níveis de orientação para o mercado cooperam com compradores fortes para construir parcerias voluntárias e mutuamente lucrativas. A implicação geral é que as unidades de commodities de mais elevado grau de orientação para o mercado exploram com sucesso estratégias de diferenciação e orientação para o mercado. A implicação também se aplica às unidades de não commodities.

\section{DISCUSSÃO}

As conclusões sustentam nossa hipótese de que, para as unidades, sejam de commodities ou de não commodities, a orientação para o mercado é uma determinante importante da lucratividade. Entre as unidades de não commodities, a relação positiva entre orientação para o mercado e lucratividade parece ser uniforme, ao passo que entre as unidades de commodities encontramos relação positiva entre orientação para o mercado/lucratividade apenas nas empresas de orientação para o mercado superior à mediana.

Para as unidades de commodities e de não commodities, os custos relativos também parecem ser importantes determinantes da lucratividade. Assim, em média, os dois tipos de empresa podem empregar estratégia de diferenciação e/ou baixo custo.

Os resultados sugerem que o crescimento do mercado é uma importante determinante da lucratividade para os dois tipos de unidade, mas as relações divergem. Para as unidades de não commodities, o crescimento do mercado a curto prazo representa uma oportunidade lucrativa, enquanto para as unidades de commodities, que em geral são menos adaptáveis do que as de não commodities, o crescimento do mercado a curto prazo parece reduzir a lucratividade.

Pode-se inferir que as empresas de commodities que apresentam substancial orientação para o mercado são capazes de dar início a programas de aumento de valor em cooperação com compradores poderosos, obtendo um resultado mutuamente lucrativo. Com efeito, as unidades de commodities mais habilitadas a criar superioridade em valor para o cliente podem até mesmo criar dependência econômica em compradores que, de outra maneira, são fortes.

A questão mais fundamental é: até que ponto a relação não linear que observamos entre orientação para 
o mercado e lucratividade nas unidades de commodities é comum a todos os tipos de unidade. Suspeitamos que ela pode ser bastante comum. O setor de produtos florestais não é o único com uma cultura voltada para produto/tecnologia. Unidades de negócio de organizações que refletem tal cultura aumentam a trancos e barrancos sua orientação para o mercado. É de se esperar, portanto, que diversos setores - especialmente os setores básicos e setores tecnológicos há muito estabelecidos - apresentem alguma forma da relação em "U" entre orientação para o mercado e lucratividade. Essa probabilidade é ainda maior quando as empresas desses setores dependem fortemente de uma abordagem por centro de vendas/telemarketing. O fundamental é perguntar até que ponto as empresas estão dispostas e habilitadas a passar com eficiência e eficácia pelos estágios de mudança cultural até atingir a elevada lucratividade de uma orientação para o mercado plenamente implementada.

Destacamos que a orientação para o mercado abrange um continuum (veja também Jaworski e Kohli, 1990). Observamos em nossa pesquisa que as unidades de mais intensa orientação para o mercado estão associadas à maior lucratividade. Mas nenhuma delas atingiu a pontuação máxima possível de orientação para o mercado. Estarão essas unidades em equilíbrio ou ainda trabalham para intensificar sua orientação para o mercado? Aplica-se aqui uma lei básica da economia: para qualquer empresa, em algum ponto o custo incremental de intensificação da orientação para o mercado irá superar o benefício incremental. Estará esse ponto na máxima orientação para o mercado possível ou próximo dela? Ou estará longe dessa marca? Haverá alguns ambientes de mercado em que as empresas tendem para um nível elevado de orientação para o mercado, assim como outros em que elas tendem a parar num nível bem mais baixo de orientação para o mercado? Em caso positivo, quais as características dos respectivos ambientes? Retornaremos a essas questões ao discutirmos aspectos importantes para pesquisas futuras.

Levando em conta a orientação para o mercado e as implicações de nossa pesquisa, acreditamos que a orientação para o mercado é relevante em muitos ambientes de mercado. Desse modo, discordamos de Miles e Snow (1978), por exemplo, que deduzem que a orientação para o mercado em alguns ambientes é simplesmente não econômica. A questão apropriada não é a orientação para o mercado em si, mas sim como uma unidade de negócio percebe seu grau ótimo de orientação para o mercado em seu ambiente atual e esperado.

\section{LIMITAÇÕES E IMPLICAÇÕES PARA PESQUISAS FUTURAS}

Restringir nosso estudo a uma única grande empresa tanto traz vantagens quanto limitações. Uma vantagem está no fato de que, com o forte e uniforme apoio recebido dos gestores da empresa, tivemos fácil acesso a diversos respondentes informados nas UENs. Também obtivemos elevada taxa de respostas, o que seria bém mais difícil se tivéssemos examinado um número equivalente de empresas independentes.

A principal limitação potencial ao uso de UENs de uma única empresa está no fato de que uma orientação corporativa abrangente poderia sobrepujar diferenças entre as orientações individuais das unidades. Mas esse problema potencial parece não ter surgido em nosso estudo, já que encontramos considerável variação entre as respostas. Na escala de 7 pontos, a faixa de respostas variou de 2,8 a 6,1 para orientação para o cliente, de 2,8 a 6,6 para orientação para o concorrente e de 2,6 a 5,8 para coordenação interfuncional (veja detalhes na Tabela 5). A variação das respostas indica que, para os três componentes hipotéticos da orientação para o mercado, não há percepções influenciadas por uma cultura corporativa abrangente.

A lógica da orientação para o mercado traz em si a implicação de que os comportamentos implícitos nos três componentes incluem sensibilidade e capacidade de resposta a todos os aspectos sociais de marketing capazes de afetar o desempenho de uma unidade a longo prazo. Mas as escalas de orientação para o cliente, orientação para o concorrente e coordenação interfuncional aqui desenvolvidas não incluem itens que representem marketing social (por exemplo, Kotler, 1984).

Em nosso estudo exploratório, considerações atinentes à validade interna muitas vezes tiveram precedência sobre as de validade externa, e os resultados, embora fortes, são necessariamente limitados no que se refere à sua aplicação generalizada. Estudos futuros ampliarão o entendimento do construto se adotarem as três sugestões de concepção de pesquisa oferecidas a seguir.

1. Uso de várias empresas como base de amostragem. Embora o acesso às equipes da alta administração das UENs respondentes e a elevada taxa de resposta que obtivemos tenham sido altamente desejáveis em termos de confiabilidade, estudos futuros poderiam se concentrar numa amostragem maior de organizações para avaliar a robustez das relações aqui encontradas entre orientação para o mercado e desempenho. 
2. Maior amostra de setores. Os ambientes organizacionais das UENs aqui estudadas são caracterizados por uma ampla variedade de estruturas de mercado, mas todas competem num mesmo e amplo setor. Estudos futuros poderiam investigar se as relações aqui encontradas se verificam nos setores de alta tecnologia e de serviços e no ambiente internacional.

3. Pesquisa de concepção longitudinal. A natureza do perfil deste estudo restringe as conclusões à relação associativa, deixando de lado a causal. O desenvolvimento de uma base de dados em série temporal e o teste da relação entre orientação para o mercado e desempenho numa estrutura longitudinal forneceria maiores esclarecimentos sobre a provável causa.

Além das sugestões acima oferecidas para modificação do desenho da pesquisa, esforços futuros também poderiam abordar as seis questões abrangentes de orientação para o mercado indicadas a seguir.

Mensuração da orientação para o lucro e foco no longo prazo. Nossa tentativa de desenvolver uma medida válida da orientação para o mercado e do foco de longo prazo como parte de um construto unidimensional de orientação para o mercado foi malsucedida. Estudos futuros poderiam abordar essa questão, incluindo itens adicionais que representem esses construtos e testando ainda sua relação com o modelo de orientação para o mercado em três componentes e com o desempenho das empresas.

Outras medidas de desempenho. Seria útil testar a relação entre orientação para o mercado e outras medidas de desempenho que possam afetar a lucratividade a longo prazo. Por exemplo, qual a relação entre orientação para o mercado para a retenção de clientes, sucesso de novos produtos e crescimento das vendas?

Equilíbrio entre os componentes de uma orientação para o mercado. Além de um exame mais detido do efeito da magnitude da orientação para o mercado sobre o desempenho, estudos futuros deveriam examinar o efeito das proporções dos componentes em uma determinada magnitude de orientação para o mercado. Alguns autores (como Peters e Austin, 1985; Peters e Waterman, 1982) sugerem que a orientação para o cliente é o componente mais importante da orientação para o mercado. A implicação é que uma dada magnitude de orientação para o mercado fortemente inclinada à orientação para o cliente teria desempenho superior a outra em que os três componentes estivessem mais equilibrados. Uma pergunta importante é se, para uma dada magnitude de orientação para o mercado, uma igualdade aproximada entre os componentes produziria, na média, lucratividade superior se comparada a uma desigualdade substancial entre os componentes, com igualdade das demais condições.

Day e Wensley (1988) sugerem que a ênfase relativa na orientação para o cliente e na orientação para o concorrente depende das características do ambiente de negócio. Essa também é uma importante questão a ser estudada.

Dimensões de marketing social. A implicação de uma dada magnitude de orientação para o mercado é que uma empresa seria sensível na mesma medida a qualquer questão ou parte interessada que pudesse afetar seu desempenho a longo prazo. Além de restrições explícitas ao desempenho (como regras antitruste e defesa do consumidor) a que uma empresa orientada para o mercado deve atender, as empresas são guiadas também por seu sistema de valores éticos e por sua percepção de responsabilidade social.

Três questões de marketing social são merecedoras de exame. Primeiro, seria interessante incluir, nas escalas de orientação para o cliente, orientação para o concorrente e coordenação interfuncional, itens que representassem marketing social para ver se apresentam forte correlação com os demais itens da escala. Segundo, a relação entre a orientação para o mercado de uma empresa e a medida de seu comportamento "socialmente responsável" poderia ser examinada. Seria de se esperar que, sendo externamente orientada, nos termos das implicações gerais da orientação para o mercado, uma empresa não apenas seria sensível ao público externo, mas também anteciparia suas preocupações. Assim, de modo geral, haveria relação entre a orientação para o mercado e a "boa cidadania"? Terceiro, há uma expectativa paralela no que tange ao público interno. Como se pode ver na análise das unidades de commodities, os dados sugerem uma relação positiva entre orientação para o mercado e a qualidade da gestão de recursos humanos. Pode muito bem existir uma forte relação entre o grau de orientação para o mercado de uma empresa e a qualidade geral de sua gestão. Essa possibilidade precisa ser mais examinada.

Determinantes da orientação para o mercado. Quais são os fatores, no nível do mercado e no nível da empresa, que mais afetam o aumento da orientação para o mercado? Que ambientes de mercado e internos estão associados aos mais elevados níveis médios de orientação para o mercado das empresas e quais estão associados aos menores níveis? Para desenvolver estratégias eficazes e eficientes de intensificação da orienta- 
ção para o mercado, os gestores precisam conhecer os fatores que limitam ou facilitam seu desenvolvimento e os que afetam seu nível ideal.

Estratégias de intensificação da orientação para o mercado. Com o desenvolvimento de uma medida válida de orientação para o mercado e a demonstração de seu efeito significativo sobre o desempenho, a pergunta mais importante para os profissionais do mercado passa a ser: "Como aumentar e sustentar uma orientação para o mercado?". Partindo de uma compreensão das determinantes da orientação para o mercado, os pesquisadores devem examinar a eficácia relativa de estratégias alternativas de intensificação e sustentação da orientação para o mercado em diferentes ambientes de mercado.

\section{CONCLUSÃO}

Nosso estudo é um primeiro passo importante para validar a relação entre orientação para o mercado e desempenho. Para os estudiosos, as implicações do estudo são claras. A pesquisa precisa ser replicada em ambientes diversos e ao longo do tempo para aumentar o grau de confiança na natureza e na solidez da teoria. Para os gestores, as implicações do estudo não são tão claras. Por causa da natureza exploratória do estudo, as conclusões são limitadas no que se refere à sua generalização, mas sugerem que - após controlar as influências importantes nos níveis do mercado e da empresa - a orientação para o mercado e o desempenho estão fortemente relacionados. Essas conclusões são totalmente condizentes com a intuição e as expectativas tanto dos estudiosos quanto dos profissionais do setor, nas últimas três décadas, com relação à natureza e aos efeitos da orientação para o mercado. As conclusões dão aos estudiosos e profissionais de marketing uma base, além da mera intuição, para recomendarem a superioridade da orientação para o mercado.

Se os resultados de réplicas de nossas pesquisas sustentarem nossas conclusões, a mensagem para os gestores será clara: uma substancial orientação para o mercado precisa ser a base da estratégia de vantagem competitiva das empresas.

\section{NOTAS}

${ }^{1}$ A distribuição do resíduo da regressão é semelhante à das variáveis individuais, ou seja, não há "caudas", e a distribuição é mais centralizada do que uma distribuição normal. Além disso, os termos de erro têm maior probabilidade de viés para a esquerda do que para a direita. Mas o desvio em relação ao formato da distribuição normal não sugere nenhuma forma clara de transformação que representasse melhoria. Muitas das variáveis de interesse são dados contínuos. Mas, em vez de usar os valores efetivos, os respondentes forneceram os dados em escalas ordinais (de 7 pontos) ou em escalas de intervalo truncado, o que resultou numa menor distribuição dos dados. Como se sabe, com dados truncados a análise por regressão ordinária dos mínimos quadrados (OLS) pode aproximar a relação com maior precisão na faixa intermediária de valores do que nas extremidades dos dados. As demais observações de praxe sobre OLS também se aplicam.

Os autores agradecem, pelos comentários, a William W. Alberts, George Brooker, Robert L. Jacobson, Peter H. Nickerson. Ronald Savitt, David H. Spain, e aos quatro revisores anônimos do JM; pelo apoio em pesquisa, a Tailan Chi, Seong Park e Bong-Ho Shin; e, pelo apoio financeiro, ao Marketing Science Institute.

\section{REFERÊNCIAS BIBLIOGRÁFICAS}

AAKER, D. A. Strategic Market Management. New York: John Wiley \& Sons, 1988.

AAKER, D. A. Managing assets and skills: the key to sustainable competitive advantage. California Management Review, v. 31, n. 2, p. 91-106, 1989.

ALDERSON, W. Marketing Behavior and Executive Action. Homewood, IL: Richard D. Irwin, 1957.

ANDERSON, P. F. Marketing, strategic planning and the theory of the firm. Journal of Marketing, v. 46, n. 2, p. 15-26, 1982.

BAIN, J. S. Industrial Organization. New York: John Wiley \& Sons, 1959.

BARRET, J. Why major account selling works. Industrial Marketing Management, n. 15, p. 63-73, 1986.

BOAL, K. B.; BRYSON, J. M. Representation, testing and policy implications of planning processes. Strategic Management Journal, v. 8, n. 3, p. $211-$ $231,1987$.

CHAMBERLIN, E. H. The Theory of Monopolistic Competition. Cambridge, MA: Harvard University Press, 1933.

CHURCHILL JR., G. A. A paradigm for developing better measures of marketing constructs. Journal of Marketing Research, v. 16, n. 1, p. 64-73, 1979.

COHEN, J.; COHEN, P. Applied Multiple Regression/Correlation Analysis for the Behavioral Sciences. Hillsdale, NJ: Lawrence Erlbaum Associates, 1975.

CRONBACH, L. Essentials of Psychological Testing. New York: Harper \& Row, 1970

DAY, G. S. Strategic Marketing Planning. New York: West Publishing Company, 1984. 
DAY, G. S.; WENSLEY, R. Assessing advantage: a framework for diagnosing competitive superiority. Journal of Marketing, v. 52, n. 2, p. 1-20, 1988.

DEMSETZ, H. Two systems of belief about monopoly. In: GOLDSCHMID, H. J.; MANN, H. M.; WESTON, J. F. (Eds.). Industrial Concentration: The New Learning. Boston: Little, Brown \& Co., 1974.

DESHPANDE, R.; WEBSTER, F. E., JR. Organizational culture and marketing: defining the research agenda. Journal of Marketing, v. 53, n. 1, p. 315,1989

DESS, G. G.; DAVIS, P. S. Porter's (1980) generic strategies as determinants of strategic group membership and organizational performance. Academy of Management Journal, v. 27, n. 3, p. 467-488, 1984.

DESS, G. G.; ROBINSON, R. B., JR. Measuring organizational performance in the absence of objective measures: the case of the privately-held firm and conglomerate business unit. Strategic Management Journal, v. 5, n. 3 , p. 265-273, 1984.

FELTON, A. P. Making the marketing concept work. Harvard Business Review, v. 37, n. 4, p. 55-65, 1959.

FORBIS, J. L; MEHTA, N. T. Value-based strategies for industrial products. Business Horizons, v. 24, n. 3, p. 32-42, 1981.

GALBRAITH, C.; SCHENDEL, D. An emprical analysis of strategy type. Strategic Management Journal, n. 4, p. 153-173, 1983.

HALL, W. K. Survival strategies in a hostile environment. Harvard Business Review, v. 58, n. 5, p. 75-85, 1980.

HANAN, M. Consultative Selling. New York: American Management Association, 1985.

HENEMAN, H. G., III. Comparisons of self and superior ratings. Journal of Applied Psychology, v. 59, n. 5, p. 638-642, 1974.

HITT, M. A.; IRELAND, R. D. Relationships among corporate-level distinctive competencies, diversification strategy, corporate structure, and performance. Journal of Management Studies, v. 23, n. 4, p. 265298, 1986.

HOUSTON, F. S. The marketing concept: what it is and what it is not. Journal of Marketing, v. 50, p. 81-87, 1986.

JACKSON, B. B. Winning and Keeping Industrial Customers. Lexington, MA: Lexington Books, 1985

JAWORSKI, B. J.; KOHLI, A. K. Market orientation: antecedents and consequences. Journal of Marketing, v. 57, n. 3, p. 53-70, 1993.
KERLINGER, F. N. Foundations of Behavioral Research. New York: Rinehart and Winston, 1973.

KOTLER, P. From sales obsession to marketing effectiveness. Harvard Business Review, v. 55, n. 6, p. 65-75, 1977.

KOTLER, P. Marketing Management: Analysis, Planning, and Control. Englewood Cliffs, NJ: Prentice-Hall, 1984.

KOTLER, P.; ANDREASEN, A. R. Strategic Marketing for Nonprofit Organizations. Englewood Cliffs, NJ: Prentice-Hall, 1987.

LEVITT, T. Marketing myopia. Harvard Business Review, v. 38, n. 4, p. 45$56,1960$.

LEVITT, T. Marketing success through differentiation of anything. Harvard Business Review, v. 58, n. 1, p. 83-91, 1990.

MCNAMARA, C. P. The present status of the marketing concept. Journal of Marketing, v. 36, n. 1, p. 50-57, 1972

MILES, R. C.; SNOW, C. C. Organizational Strategy, Structure, and Process. New York: McGraw-Hill, 1978.

NUNNALLY, J. C. Psychometric Theory. New York: McGraw-Hill, 1978.

OHMAE, K. The mind of the Strategist. New York: McGraw-Hill, 1982.

PEARCE, J. A.; ROBBINS, D. K.; ROBINSON, R. B. The impact of grand strategy and planning formality on financial performance. Strategic Management Journal, v. 8, n. 2, p. 125-134, 1987.

PETERS, T. J.; AUSTIN, N. A Passion for Excellence. New York: Random House, 1985

PETERS, T. J.; WATERMAN, R. H. In Search of Excellence. Cambridge, MA: Harper \& Row, 1982.

PORTER, M. Competitive Strategy. New York: The Free Press, 1980.

PORTER, M. Competitive Advantage. New York: The Free Press, 1985.

RUCKERT, R. W.; WALKER, O. C., JR. Interactions between marketing and $R \& D$ departments in implementing different business strategies. Strategic Management Journal, v. 8, p. 233-248, 1987a.

RUCKERT, R. W. WALKER, O. C., JR. Marketing's interaction with other functional units: a conceptual framework and empirical evidence. Journal of Marketing, v. 51, n. 1, p. 1-19, 1987b. 
SCHERER, F. M. Industrial Market Structure and Economic Performance. Chicago: Rand McNally, 1980.

SHAPIRO, B. P. What the hell is 'market oriented'? Harvard Business Review, v. 66, n. 6 , p. $119-125,1988$

WEBSTER, F. E., JR. Rediscovering the marketing concept. Business Horizons, v. 31, p. 29-39, 1988

WIND, Y.; ROBERTSON, T. S. Marketing strategy: new directions for theory and research. Journal of Marketing, v. 47, n. 2, p. 12-25, 1983.

ZEITHAML, V. A. Consumer perceptions of price, quality, and value: a means-end model and synthesis of evidence. Journal of Marketing, v. 52, n. 3, p. 2-22, 1988
Este artigo é de propriedade exclusiva da American Marketing Association, tanto quanto sua licença para uso, e é protegida pelo Copyright e pelas leis de propriedade intelectual. O uso deste material é dirigido para uso pessoal e não comercial. Qualquer outro tipo de uso deste artigo é estritamente proibido. O usuário não poderá modificar, publicar, transmitir, participar na transferência ou na venda do material, reproduzir, criar trabalhos derivados (incluindo material didático) deste, distribuir, realizar apresentação, ou qualquer modo de utilização do conteúdo inteiro ou em partes. Este artigo, protegido pelo Copyright, foi traduzido objetivando expressamente a essa publicação. A American Marketing Association não assumirá a responsabilidade por erros de interpretação causados pela tradução. Este artigo foi reproduzido com a autorização do Journal of Marketing, publicado pela American Marketing Association. O artigo "The effect of a market orientation on business profitability", dos autores John C. Narver e Stanley F. Slater, foi originalmente publicado no Journal of Marketing, volume 54 (October 1990), p. 20-35.

\section{Artigo convidado. Aprovado em 01.02.2006.}

\section{John C. Narver}

Professor emérito de Marketing da Business School - University of Washington.

Interesse de pesquisa nas áreas de estratégia de marketing, cultura de negócios orientada para o consumidor, marketing business-to-business, análise da competição.

E-mail: jnarver@u.washington.edu

Endereço: University of Washington, Business School, Marketing and International Business

Department, Box 353200, Seattle, WA - USA, 98195-3200.

\section{Stanley F. Slater}

Professor de Administração de Empresas no College of Business - Colorado State University. Interesse de pesquisa nas áreas de orientação para o mercado e sucesso organizacional, papel do marketing na implementação de estratégica, estratégias para a gestão da inovação.

E-mail: stan.slater@business.colostate.edu

Endereço: 212 Rockwell Hall, College of Business, Fort Collins, CO - USA, 80523. 